\title{
OPTIMALISASI PEMECAHAN MASALAH TRANSPORTASI MENGGUNAKAN METODE NWC, INPEKSI, DAN VAM
}

\author{
Oleh \\ Nyoman Martha Adiwikanta, Ni Ketut Kertiasih \\ Jurusan Manajemen Informatika, FTK, UNDIKSHA
}

\begin{abstract}
ABSTRAK
Sistem optimalisasi dalam pemecahan masalah transportasi menggunakan metode NWC (north west corner), INPEKSI (matrik minimum), dan VAM (Vogel Approximation Method) adalah sebuah sistem yang dibangun dan difungsikan sebagai sistem yang diharapkan mampu mengetahui biaya paling minimum dalam pengalokasian barang dengan membandingkan tiga metode tersebut. Sistem ini memiliki kelebihan dalam proses input, keakuratan proses perhitungan dan proses pengerjaan lebih cepat dari proses perhitungan secara manual. Sistem ini digunakan untuk melakukan proses input jumlah gudang, input jumlah pabrik, biaya satuan dari tiap-tiap pabrik menuju tiap-tiap gudang, hasil produksi tiap pabrik, dan kapasitas gudang, selanjutnya dilakukan proses perhitungan dengan menggunakan ketiga metode tersebut. Sistem ini dibangun dengan menggunakan visual basic 6.0 dan microsoft office accsess 2007 sebagai basis datanya. Sistem ini diharapkan dapat mempermudah pengguna dalam penyelesaian masalah pendistribusian barang dari pabrik ke masing-masing gudang.
\end{abstract}

Kata-kata kunci : Optimalisasi, NWC, INPEKSI dan VAM

\begin{abstract}
Optimization system in solving transportation problems using methods NWC (north west corner), inspections (minimum matrix), and VAM (Vogel Approximation Method) is a system built and functioned as a system that is expected to determine the minimum cost in the allocation of goods by comparing three such methods. This system has advantages in the input process, the accuracy of the calculation process and the process of working faster than manual calculation process. This system is used to perform the process of entering the warehouse number, the number of factories, each unit cost of each factory to the warehouse, the production of each factory, and warehouse capacity calculation process is then performed using these three methods. The system is built using Visual Basic 6.0 and Microsoft Office accsess 2007 as the database manager. The system is expected to facilitate the user in the resolution of the problem of distribution of goods from the factory to each warehouse.
\end{abstract}

Key words: Optimization, NWC, INPEKSI and VAM 


\section{PENDAHULUAN}

Metode transportasi dalam program linear adalah suatu metode yang digunakan untuk mengatur distribusi dari sumber-sumber yang menyediakan produk yang sama atau sejenis ke tempat tujuan secara optimal. Pada umumnya masalah transportasi berhubungan dengan distribusi suatu produk tunggal dari beberapa sumber menuju beberapa tujuan. Masalah transportasi timbul karena adanya kesalahaan pengalokasian suatu barang. Masalah transportasi jumlah hasil produksi tiap-tiap pabrik diketahui, daya tampung gudang dan biaya angkut atau distribusi tiap satuan sudah diketahui (Mulyono, 2002).

Pemecahan masalah transportasi dapat dilakukan secara manual. Pemecahan masalah transportasi memiliki beberapa kelemahan atau kekurangan diantaranya waktu perhitungan relatif lama dan kemungkinan terjadi kesalahan dalam proses perhitungan secara manual. Kemajuan teknologi yang sangat pesat dapat membantu kehidupan manusia dalam berbagai bidang termasuk dalam bidang ilmu matematika. Pengembangan sistem optimalisasi pemecahan masalah transportasi menggunakan metode NWC (North West Corner), INPEKSI (matrik minimum), dan VAM (Vogel Approximation Method) dipilih menjadi alternatif untuk membantu menyelesaikan kelemahan atau kekurangan masalah transportasi secara manual.

Masalah transportasi pernah diangkat sebagai topik penelitian oleh I Made Dedik Parnanda Satriadi tahun 2010 yang membandingkan metode antara NWC (north west corner) dan Stepping stones untuk memecahkan masalah alokasi pendistribusian barang. Biaya minimal distribusi barang diperoleh melalui pengangkutan barang dari tempat asal ke tempat tujuan.

Permasalahan yang akan dikaji terkait dengan transportasi di dalam pendistribusian barang dengan menggunakan metode NWC (north west corner), INPEKSI (matrik minimum), dan VAM (vogel approximation method). Pemecahan masalah transportasi dengan menggunakan metode NWC (north west corner), INPEKSI (matrik minimum), dan VAM (vogel approximation method) diharapkan dapat mendistribusikan barang dengan biaya yang lebih minimal bila dibandingkan dengan menggunakan metode NWC (north west corner) dan Stepping stones. 


\section{METODE PENELITIAN}

Dalam pengerjaan Sistem optimalisasi pemecahan masalah transportasi dengan metode NWC (North West Corner), INPEKSI (matrik minimum), dan VAM (Vogel Approximation Method) model pendekatan yang digunakan adalah model Waterfall. Model ini melakukan pendekatan secara sistematis dan urut mulai dari level kebutuhan sistem lalu menuju ke tahap analisis, desain, koding, testing / verification, dan maintenance. Disebut dengan waterfall karena tahap demi tahap yang dilalui harus menunggu selesainya tahap sebelumnya dan berjalan berurutan.

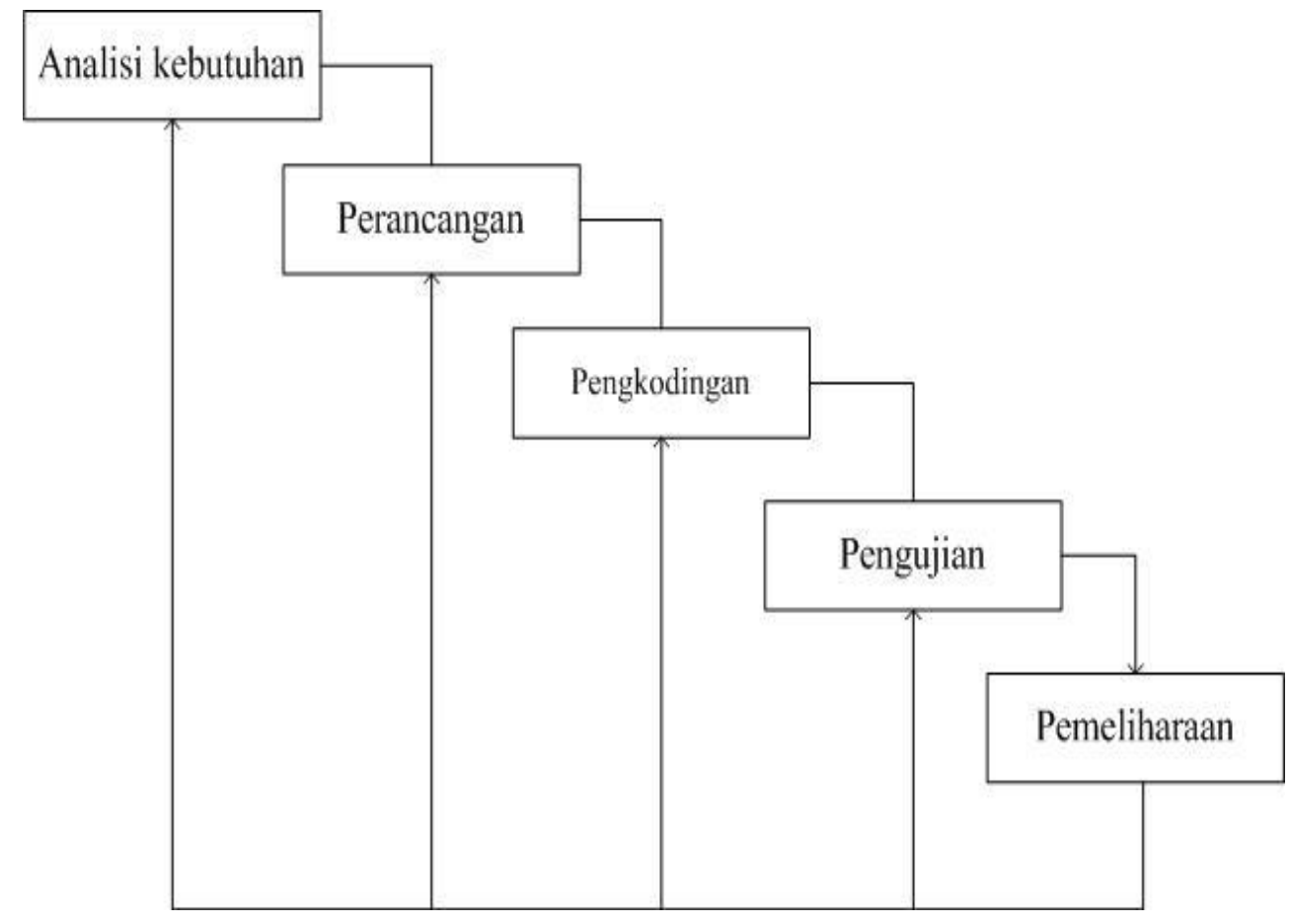

Gambar 1. Pemodelan Waterfall

\section{a. Analisi kebutuhan}

Analisis kebutuhan disini menyangkut apa saja yang akan diperlukan untuk mengembangkan sistem ini. Dengan melakukan pengumpulan data, dimana pengumpulan data dilakukan dengan studi kepustakaan. Studi kepustakaan dilakukan dengan mengumpulkan data yang ada hubungannya dengan topik baik 
dari sumber yang berupa artikel-artikel maupun sumber lainnya. Analisis kebutuhan juga meliputi kebutuhan pada hardware dan juga software apa saja yang diperlukan dalam pengembangan sistem informasi ini.

\section{b. Perancangan}

Perancangan sistem ini merupakan tahap pengimplementasian setelah dilakukannya analisis kebutuhan, yaitu perancangan antarmuka sistem dengan menggunakan software.

\section{c. Pengkodingan}

Untuk dapat dimengerti oleh mesin, dalam hal ini adalah komputer, maka desain tadi harus diubah bentuknya menjadi bentuk yang dapat dimengerti oleh mesin, yaitu ke dalam bahasa pemrograman melalui proses koding. Tahap ini merupakan implementasi dari tahap desain yang secara teknis nantinya dikerjakan oleh programmer.

\section{d. Pengujian}

Tahap pengujian dilakukan jika program sudah selesai dibuat. Proses pengujian ini bertujuan untuk mengetahui apakah sistem yang dibuat sudah sesuai dengan yang diharapkan disini akan diuji apakah masih ada kesalahan pada sistem baik dari segi koding maupun rancangannya.

\section{e. Pemeliharaan atau perawatan}

Mengoperasikan program dilingkungannya dan melakukan pemeliharaan, seperti penyesuaian atau perubahan karena adaptasi dengan situasi sebenarnya.

\section{HASIL PENELITIAN DAN PEMBAHASAN}

\subsection{Hasil Penelitian}

Sistem Opimalisasi Pemecahan Masalah Transportasi Menggunakan Metode NWC (north west corner), INPEKSI (matrik minimum), dan VAM (Vogel Approximation Method) ini user yang memiliki hak akses dalam melakukan 
manipulasi semua data yang terdapat dalam sistem. Adapun halaman utama yang dapat dilihat pada gambar 2 berikut.

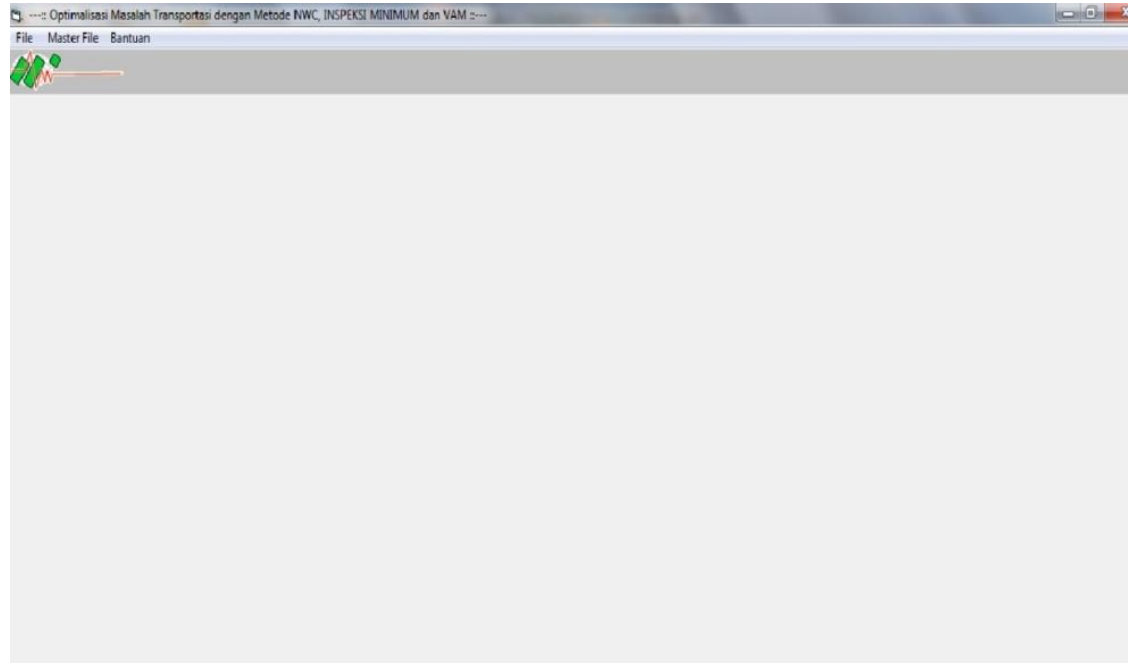

Gambar 2. Tampilan Form Utama

Berdasarkan gambar diatas user dapat melakukan input data gudang, data pabrik, hasil metode NWC, hasil metode INSPEKSI dan VAM, proses penyelesaian dengan metode NWC seperti terlihat pada gambar 3 berikut.

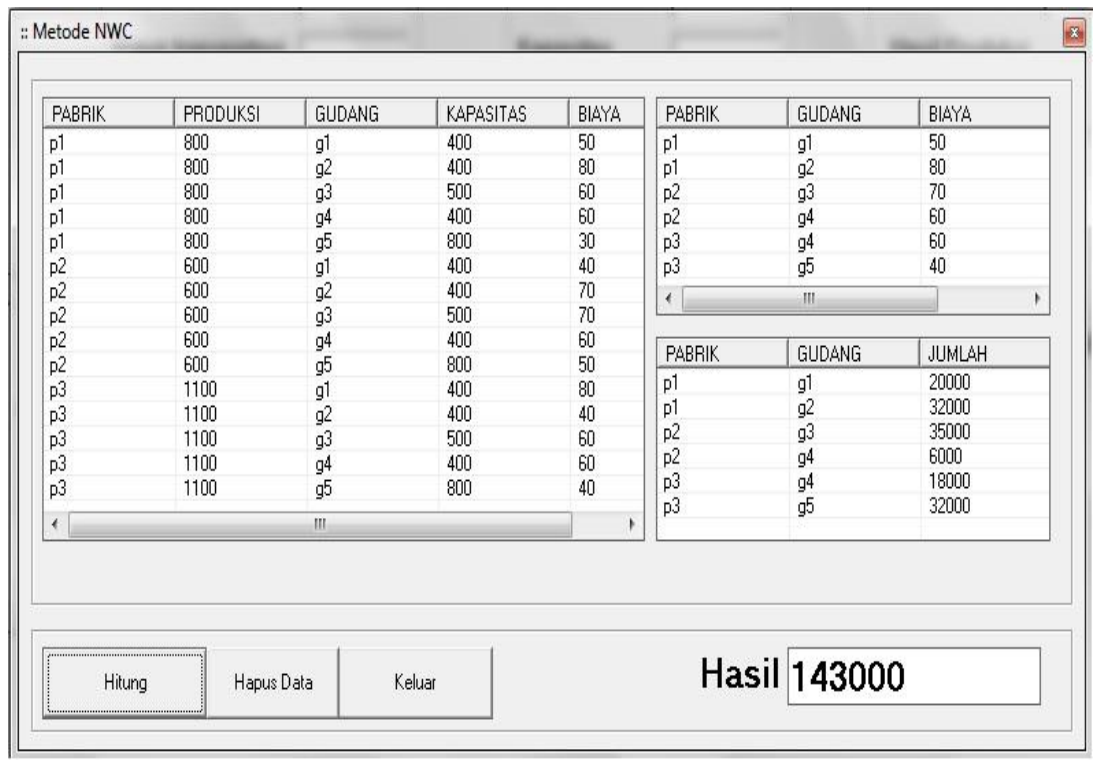

Gambar 3. Tampilan Penyelesaian dengan metode NWC 
Berdasarkan gambar diatas user dapat melakukan hapus data hasil, menghitung dengan metode NWC dan keluar dari program.

\subsection{Pembahasan}

program linear merupakan teknik riset operasional (operation research technique) yang telah dipergunakan secara luas dalam berbagai jenis masalah manajemen. Banyak keputusan manajemen produksi dan inventori mencoba membuat agar penggunaan sumber-sumber daya manufakturing menjadi lebih efektif dan efisien. Sumber-sumber daya manufakturing seperti: mesin, tenaga kerja, modal, waktu, dan bahan baku digunakan dalam kombinasi tertentu yang paling optimum untuk menghasilkan produk (barang/jasa). Dengan demikian program linear dipergunakan untuk membantu manajer-manajer guna merencanakan dan membuat keputusan tentang pengalokasian sumber-sumber daya yang optimum (Gaspersz, 2001).

Sejak tahun lima puluhan program linear tersebut berkembang dengan pesat di bidang kemiliteran untuk menyusun strategi perang maupun di dalam bidang bisnis untuk mencapai pemasukan maksimum dan pengeluaran minimum. Zaman sekarang penggunaan program linear bukan saja terbatas pada bidang kemiliteran, bidang ekonomi perusahaan yang sifatnya micro, akan tetapi sudah meluas terutama sekali di dalam perencanaan pembangunan ekonomi nasional yang makro sifatnya misalnya dalam penentuan allocation of investments ke dalam sektor-sektor perekonomian, rotation corp policy peningkatan penerimaan devisa dan lain sebagainya.

Metode transportasi adalah metode yang digunakan untuk mengatur distribusi dari sumber-sumber yang menyediakan produk yang sama ke tempattempat yang membutuhkan secara optimal. Alokasi produk ini harus diatur sedemikian rupa, karena terdapat perbedaan biaya-biaya alokasi dari satu sumber ke suatu tempat tujuan juga berbeda-beda (Gaber, 2009). 
Sistem Opimalisasi Pemecahan Masalah Transportasi Menggunakan Metode NWC (north west corner), INPEKSI (matrik minimum), dan VAM (Vogel Approximation Method) adalah sistem yang digunakan untuk memperoleh biaya paling minimum dari pebandingan ketiga metode yang digunakan. Sistem ini diharapkan mampu membantu masyarakat umum yang sedang mengalami masalah dalam pengalokasian barang dan mampu memperoleh informasi biaya paling minimum. Implementasi sistem optimalisasi pemecahan masalah transportasi dengan metode NWC (North West Corner), INPEKSI (matrik minimum), dan VAM (Vogel Approximation Method) dengan menggunakan bahasa pemrograman visual basic 6.0 dan microsoft office accsess 2007 sebagai basis datanya.

\section{PENUTUP}

Sistem optimalisasi pemecahan masalah transportasi dengan metode NWC, INPEKSI, dan VAM yang terdiri dari rancangan sistem, rancangan basis data, dan rancangan antarmuka. Rancangan sistem digambarkan dengan menggunakan diagram konteks dan DFD level 1. Untuk rancangan basis data menggunakan beberapa tabel yaitu tabel biaya, tabel gudang, tabel pabrik dan tabel hasil. Untuk rancangan antarmuka terdiri dari rancangan antarmuka menu utama, rancangan form metode NWC, rancangan form metode INPEKSI, dan rancangan form metode VAM. Diimplementasikan sebuah sistem optimalisasi pemecahan masalah transportasi dengan metode NWC, INPEKSI, dan VAM menggunakan bahasa pemrograman visual basic 6.0, microsoft office accsess 2007 sebagai pengelola basis datanya

Dari simpulan di atas dapat disarankan beberapa hal yang perlu dikembangkan selanjutnya pada sistem optimalisasi pemecahan masalah transportasi dengan metode NWC, INPEKSI, dan VAM. Pada pengembangan selanjutnya, sistem optimalisasi pemecahan masalah transportasi dengan metode NWC, INPEKSI, dan VAM mampu menampilkan hasil akhir dengan bantuan macromedia flash agar lebih mempermudah user mengetahui proses penyelesaian dari beberapa metode tersebut. Sistem yang akan dikembangkan selanjutnya diharapkan dapat memiliki tampilan 
yang lebih menarik dan lebih dinamis yang bertujuan memudahkan user dalam penggunaan.

\section{DAFTAR PUSTAKA}

Gaber, Elsharawy. 2009. International Journal of Computer Science and Network Security, VOL.9 No.2, February. tersedia pada http://paper.ijcsns.org/ 07_book/200902/20090248.pdf (diakses tanggal 19 juni 2012)

Gaspersz, Vincent. 2001. Aplikasi Linear Programming (LP) Dalam Konsep The Theory Of Constraints (Toc), Jurnal Teknologi Industri V(3) Juli

Mulyono, Sri. 2002. Riset Operasi. Jakarta: Lembaga Penerbit Fakultas Ekonomi UI 